\title{
Molecular features of glioblastomas in long-term survivors compared to short-term survivors - a matched-pair analysis
}

\author{
Vivien N. Sommerlath ${ }^{1 \dagger}$, Daniel Buergy ${ }^{1 \dagger}$, Nima Etminan², Stefanie Brehmer ${ }^{2}$, David Reuss ${ }^{3}$, Gustavo R. Sarria ${ }^{4}$,
} Marie-Christin Guiot ${ }^{5}$, Daniel Hänggi ${ }^{6}$, Frederik Wenz ${ }^{7}$, Kevin Petrecca ${ }^{8}$ and Frank A. Giordano ${ }^{4^{*}}$ (D)

\begin{abstract}
Background: Although glioblastoma (GB) is associated with a devastating prognosis, a small proportion of patients achieve long-term survival rates. We herein present a matched-pair analysis of molecular factors found in long- and short-term survivors (LTS, STS).

Methods: We performed a cross-institutional analysis of 262 patient records and matched a group of 91 LTS ( $\geq 3$ years) with two groups of STS (STS-1, $n=91$; STS-2, $n=80$ ). Matching was performed according to age, Karnofsky Performance Status, initial therapy and adjuvant therapy. Molecular factors were compared between LTS (total of 91 patients) v. STS-1, and LTS (subgroup of 80 patients) v. STS-2. We included glial fibrillary acidic protein (GFAP), O6-methylguanine-DNA methyltransferase (MGMT) promoter methylation, isocitrate dehydrogenase 1 (IDH-1); furthermore, the proliferation index was analyzed (Ki-67/MIB-1).

Results: IDH-1 and decreased Ki-67 were numerically associated with LTS but the difference was only significant compared to STS-1 (n.S. v. STS-2). LTS was associated with MGMT promoter hypermethylation ( $p=0.013$ and $p=0.022)$ and GFAP expression ( $p<0.001$ and $p=0.001$ ). Positivity for both factors combined compared to negativity for one factor occurred more often in the LTS group ( $p=0.002$ and $p=0.006$ ); negativity for both factors combined did not occur in the LTS group.

Conclusion: In this retrospective analysis, GFAP expression and MGMT promoter methylation were associated with LTS. Given the hypothesis-generating nature of our study, these observations should be confirmed in prospective clinical trials.
\end{abstract}

Keywords: Glioblastoma, GBM, Prognostic factors, GFAP, MGMT

\section{Introduction}

Glioblastoma (GB) represents the most common primary malignancy of the brain [1] and it is known for having one of the worst survival rates among all cancers $[2,3]$.

\footnotetext{
*Correspondence: frank.giordano@ukbonn.de

${ }^{\dagger}$ Vivien N. Sommerlath and Daniel Buergy have contributed equally to this work.

${ }^{4}$ Department of Radiation Oncology, University Hospital Bonn, University of Bonn, Venusberg-Campus 1, 53127 Bonn, Germany

Full list of author information is available at the end of the article
}

Nevertheless, a small proportion of patients diagnosed with GB achieves long-term survival [4]; available data indicate that 2 to $5 \%$ of patients survive 3 years or more, thus classified as long-term survivors (LTS) $[5,6]$.

The 2016 World Health Organization (WHO) classification classifies gliomas not only based on histopathologic features but also on molecular [7] parameters. These include $1 \mathrm{p} / 19 \mathrm{q}$ codeletion for oligodendroglial tumors but not for anaplastic astrocytoma or GB; furthermore, astrocytoma, including $\mathrm{GB}$ are classified as isocitrate

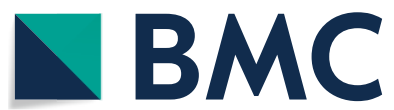

(c) The Author(s) 2022. Open Access This article is licensed under a Creative Commons Attribution 4.0 International License, which permits use, sharing, adaptation, distribution and reproduction in any medium or format, as long as you give appropriate credit to the original author(s) and the source, provide a link to the Creative Commons licence, and indicate if changes were made. The images or other third party material in this article are included in the article's Creative Commons licence, unless indicated otherwise in a credit line to the material. If material is not included in the article's Creative Commons licence and your intended use is not permitted by statutory regulation or exceeds the permitted use, you will need to obtain permission directly from the copyright holder. To view a copy of this licence, visit http://creativecommons.org/licenses/by/4.0/. The Creative Commons Public Domain Dedication waiver (http://creativecommons.org/publicdomain/zero/1.0/) applies to the data made available in this article, unless otherwise stated in a credit line to the data. 
dehydrogenase (IDH)-mutant or wildtype (or NOS in inconclusive cases). The most common IDH mutation which accounts for about $90 \%$ of all identified $I D H$ mutations is $I D H 1 \mathrm{R} 132 \mathrm{H}$ [8]. Another relevant molecular feature includes O6-methylguanine-DNA methyltransferase $(M G M T)$ promoter methylation. MGMT is a DNA repair enzyme. In case of $M G M T$ gene promoter methylation, the gene is silenced thereby impeding DNA damage repair caused by alkylating agent chemotherapy leading to an increased effectiveness of chemotherapy $[9,10]$. The prognostic value of MGMT promoter methylation for progression-free survival (PFS) and overall survival (OS) has been suggested by multiple studies and metaanalysis (e. g. Zhao et al. [11]). Tumor growth fractions using the Ki-67 index in GB have been studied using different antibodies, including Molecular Immunology Borstel-1 (MIB-1) which has been used to label Ki-67 in glioma samples by multiple groups [12-14]; however, the prognostic relevance of such approaches remains uncertain with conflicting results in multiple studies [12-15]. Finally, glial fibrillary acidic protein (GFAP) has been proposed as a diagnostic marker for GB $[16,17]$. Loss of GFAP in astrocytoma has been associated with highgrade tumors $[18,19]$ and cellular loss is associated with faster tumor growth [20]. However, rodent models indicated that loss of GFAP does not contribute directly to tumor progression [21] and its prognostic relevance is not well-established.

We conducted a bi-institutional matched-pair analysis to evaluate which of the aforementioned histopathologic or molecular parameters might be associated with OS in patients with GB.

\section{Patients and methods}

In this cross-institutional matched-pair analysis, patients from the Neurological Institute Montreal, McGill University, Canada and from the department of Radiation Oncology, University Medical Center Mannheim, Germany were included. Local institutional review board (IRB) approval was obtained for this study (2013-832RMA). We identified a cohort of LTS with an OS of 36 months or longer and matched them to two cohorts of STS (STS-1 and STS-2). Matching of patients was performed according to age, Karnofsky Performance Status (KPS), initial therapy and adjuvant therapy. Extent of surgery was estimated using surgical reports. Most patients (91.6\%) were treated between 2006 and 2018 with $8.4 \%$ of patients diagnosed between 2001 and 2005.

Histopathological parameters which were analyzed in this study included Ki-67 which was evaluated using the MIB-1 antibody or a Ki-67 antibody as part of the clinical routine workup. Furthermore, GFAP expression in available tumor samples was classified as positive, vs. negative. Tumor samples in which GFAP expression was partially lost were counted as negative. MGMT promoter expression was classified as methylated or unmethylated. For this study, staining for IDH1 R132h mutations was performed and either classified as mutated or wildtype; sequencing results for other $I D H$ mutations in case of IDH1 R132h wildtype were not analyzed in this study.

\section{Statistical analysis}

We applied the McNemar test for dichotomous variables in the matched-pair comparison; in case of $<25$ discordant cells, the binomial exact test was used. Nonparametric continuous variables in the matched-pair comparison were analyzed using the Wilcoxon test. All variables which were significant in the first comparison (LTS v. STS-1) were reanalyzed in a confirmation analysis using the 2nd STS-2 match which was used as a confirmation set for STS but no second dataset was available for the LTS group. Statistical significance threshold was set at $0.05(p<0.05)$; furthermore, both STS-1 and STS-2 were required to be significantly different compared to the LTS; we did not additionally account for multiple testing. Finally, all significant variables were analyzed in a Kaplan-Meier model to estimate the relevance of the clinical benefit in months. Statistical analyzes were performed using $\mathrm{R}$ [22], a language and environment for statistical computing or SPSS (IBM, Armonk, NY, USA).

\section{Results}

The primary cohort consists of 91 LTS, they were matched to an STS cohort $(n=91)$; furthermore, we identified a second cohort of STS $(n=80)$ to match them with 80 patients of the original LTS group.

\section{Clinical parameters}

Median age for LTS, STS-1, and STS- 2 were 54, 56, and 55.5 years, respectively. At least partial surgical resection as primary treatment was performed in $94.5 \%, 94.5 \%$, and $95 \%$ while biopsy only was performed in $5.5 \%, 5.5 \%$, and $5 \%$ of patients. Primary tumor locations were left-sided in $49.5 \%, 46.2 \%$, and $53.8 \%$ and both-sided in $3.3 \%, 6.6 \%$, and $3.8 \%$ of patients. All clinical parameters of LTS, STS1 , and STS-2 and the 80-patient subgroup of LTS which were matched to STS-2 are detailed in Table 1.

In LTS, STS-1, and STS-2 89\%, 95.6\% and $93.8 \%$ of patients had received radiochemotherapy with a median radiotherapy dose of $60 \mathrm{~Gy}$ (range: 7-68 Gy) in all groups (statistical average: $58.9 \mathrm{~Gy}, 58.6 \mathrm{~Gy}$, and $57.8 \mathrm{~Gy}$ for LTS, STS-1, and STS-2, respectively). $8.8 \%, 4.4 \%$ and $6.3 \%$ of LTS, STS- 1 and STS- 2 received radiotherapy alone. After completion of radiotherapy ( \pm concurrent chemotherapy) adjuvant chemotherapy was given in $89.0 \%, 79.1 \%$ 
Table 1 Clinical features of analyzed patients

\begin{tabular}{|c|c|c|c|c|c|c|}
\hline Clinical features & Specification & All & LTS $(n=91)$ & STS-1 $(n=91)$ & $\begin{array}{l}\text { LTS (subgroup, } \\
n=80 \text { ) }\end{array}$ & STS-2 $(n=80)$ \\
\hline KPS & $\begin{array}{l}\text { Median } \\
\text { (range) }\end{array}$ & $\begin{array}{l}80 \\
(30-100)\end{array}$ & $\begin{array}{l}80 \\
(30-100)\end{array}$ & $\begin{array}{l}80 \\
(40-100)\end{array}$ & $\begin{array}{l}70 \\
(30-100)\end{array}$ & $\begin{array}{l}80 \\
(30-100)\end{array}$ \\
\hline Age & $\begin{array}{l}\text { Median } \\
\text { (range) }\end{array}$ & $\begin{array}{l}55 \\
(11-84)\end{array}$ & $\begin{array}{l}54 \\
(22-77)\end{array}$ & $\begin{array}{l}56 \\
(11-84)\end{array}$ & $\begin{array}{l}56 \\
(22-77)\end{array}$ & $\begin{array}{l}55.5 \\
(15-77)\end{array}$ \\
\hline \multirow[t]{2}{*}{ Gender (\%) } & Female & 42.7 & 45.1 & 52.7 & 42.5 & 28.8 \\
\hline & Male & 57.3 & 54.9 & 47.3 & 57.5 & 71.3 \\
\hline \multirow[t]{2}{*}{ Surgery/biopsy (\%) } & Surgery & 94.7 & 94.5 & 94.5 & 95.0 & 95.0 \\
\hline & Biopsy & 5.3 & 5.5 & 5.5 & 5.0 & 5.0 \\
\hline Dose & $\begin{array}{l}\text { Median } \\
\text { (range) }\end{array}$ & $\begin{array}{l}60 \\
(7-68)\end{array}$ & $\begin{array}{l}60 \\
(37.5-60)\end{array}$ & $\begin{array}{l}60 \\
(16-68)\end{array}$ & $\begin{array}{l}60 \\
(37.5-60)\end{array}$ & $\begin{array}{l}60 \\
(7-62)\end{array}$ \\
\hline \multirow[t]{2}{*}{ Multifocal* $(\%)$} & Yes & 65.1 & 50.0 & 81.3 & 50.0 & 66.7 \\
\hline & No & 34.9 & 50.0 & 18.8 & 50.0 & 33.3 \\
\hline
\end{tabular}

* Results refer to patients in whom CT scans were available

and $82.5 \%$ in LTS, STS-1 and STS-2 (mostly including TMZ $82.4 \%, 70.3 \%$ and $76.3 \%$ of the cases).

\section{Survival, histopathological and molecular markers}

After a median follow-up of 16 months (range 1-156) (53.3, 9.6, and 11.8 months for LTS, STS-1, and STS-2, respectively), the median OS in the full LTS cohort and in the partial LTS cohort which included the 80 patients matched to STS-2 were not reached (lower bound of the 95\%-confidence interval also not reached). Median OS in the first matched STS cohort of 91 patients (STS-1) was 13.4 months (12.2-20.2). In the 2nd matched STS cohort (STS-2) for which 80 patients could be identified, median OS was 16.4 months (13.6-19.4). Kaplan-Meier curves for both STS groups and for the full and the partial LTS group are shown in Additional file 1: Figures S1ab. Growth fraction (Ki-67) of tumors was available in 208 samples (79.4\%) out of which 126 had been processed using the MIB-1 antibody. We identified a significantly lower Ki-67 index in the LTS group when compared to STS-1 (median: 18\% (range 5-60\%) v. 30\% (range 8-90\%); $p<0.001$ ); however, the difference was only a trend in the control comparison out of 80 LTS patients with the STS-2 group (20\% v. 25\%; $p=0.085)$. Data on Ki-67 were unavailable in 54 patients. IDH1 R132h staining was done in 136 samples; out of patients with available data, mutations were present in $15.4 \%$ of patients in the LTS group which was significantly higher compared to the STS-1 group $(7.3 \% ; p=0.031)$ but not compared to the 2 nd control match (STS-2; 11.9\%; $p=0.125)$. MGMT methylation was unknown in $43.9 \%$ of patients; in patients with available data positive methylation was observed more frequently in the LTS group (70.9\%) compared to STS-1 (49\%; $p=0.013)$ and STS-2 $(37.2 \% ; p=0.022)$. GFAP expression was only categorized as positive if expression was detected in all analyzed slides; if GFAP expression was lost in a single fraction of tumor cells the tumor was classified to be overall negative. GFAP expression data were available in $80.2 \%$ of patients; in the LTS group, the frequency of GFAP-positive tumors was higher (94.4\%) compared to STS-1 (61.6\%; $p<0.001)$, and STS-2 (64.6\%; $p=0.001)$, both of which included more tumors which were at least partially negative for GFAP (STS-1: 38.4\%; STS-2: 35.4\%). All molecular features for LTS, STS-1, and STS-2 groups are shown in Table 2. Both MGMT and GFAP were additionally analyzed using Kaplan-Meier models for the overall population (LTS, STS-1, and STS2). These models are shown in Fig. 1a, b, both showed a significant association of MGMT and GFAP expression with OS $(p=0.0012$ for MGMT and $p=0.0022$ for GFAP). Expression of GFAP was not associated with MGMT hypermethylation in the overall study cohort and both factors were analyzed combined, negativity for both factors was associated with a worse outcome compared to positivity for one $(p=0.038)$; positivity for both factors was associated with better outcomes compared to positivity for one ( $p=0.01$; see Fig. 2$)$. Positivity for both factors (GFAP positive and MGMT methylated) also occurred more frequently in the group of LTS (66\% of patients with available data on both) compared to both STS groups $(28.6 \%$ and $p=0.002$ for STS-1; $25 \%$ and $p=0.006$ for STS-2). There were no patients who were negative for both factors in the LTS group while STS-1 and STS-2 included $19 \%$ and $25 \%$ out of those with available data, respectively.

\section{Discussion}

The aim of our study was to evaluate prognostic molecular factors in a large sample of GB patients who achieved a long-term survival. Several clinical and therapeutic 
Table 2 Molecular features of analyzed patients

\begin{tabular}{|c|c|c|c|c|c|c|}
\hline Molecular features & Specification & All & LTS $(n=91)$ & STS-1 $(n=91)$ & $\begin{array}{l}\text { LTS (subgroup, } \\
\mathrm{n}=80 \text { ) }\end{array}$ & STS-2 $(n=80)$ \\
\hline \multirow[t]{3}{*}{ GFAP* (\%) } & Positive & 73.8 & 94.4 & 61.6 & 93.5 & 64.6 \\
\hline & Partially negative & 25.2 & 5.6 & 37.0 & 6.5 & 33.8 \\
\hline & Negative & 1.0 & 0 & 1.4 & 0 & 1.5 \\
\hline \multirow[t]{2}{*}{ MGMT* (\%) } & Methylated & 53.7 & 70.9 & 49.0 & 71.1 & 37.2 \\
\hline & Unmethylated & 46.3 & 29.1 & 51.0 & 28.9 & 62.8 \\
\hline \multirow[t]{2}{*}{ IDH1R132H* (\%) } & Positive & 11.0 & 15.4 & 7.3 & 16.7 & 11.9 \\
\hline & Negative & 89.0 & 84.6 & 92.7 & 83.3 & 88.1 \\
\hline MIB1 & $\begin{array}{l}\text { Median } \\
\text { (range) }\end{array}$ & $\begin{array}{l}20 \\
(3-90)\end{array}$ & $\begin{array}{l}18 \\
(5-60)\end{array}$ & $\begin{array}{l}25 \\
(8-50)\end{array}$ & $\begin{array}{l}18 \\
(5-60)\end{array}$ & $\begin{array}{l}25 \\
(3-90)\end{array}$ \\
\hline Ki67 & $\begin{array}{l}\text { Median } \\
\text { (range) }\end{array}$ & $\begin{array}{l}25 \\
(8-90)\end{array}$ & $\begin{array}{l}20 \\
(8-60)\end{array}$ & $\begin{array}{l}30 \\
(10-90)\end{array}$ & $\begin{array}{l}25 \\
(10-60)\end{array}$ & $\begin{array}{l}25 \\
(10-80)\end{array}$ \\
\hline Ki67/MIB1 & $\begin{array}{l}\text { Median } \\
\text { (range) }\end{array}$ & $\begin{array}{l}25 \\
(3-90)\end{array}$ & $\begin{array}{l}18 \\
(5-60)\end{array}$ & $\begin{array}{l}30 \\
(8-90)\end{array}$ & $\begin{array}{l}20 \\
(5-60)\end{array}$ & $\begin{array}{l}25 \\
(3-90)\end{array}$ \\
\hline \multirow[t]{4}{*}{ GFAP/MGMT* (\%) } & GFAP+/MGMT+ & 42 & 66.0 & 28.6 & 65.9 & 25.0 \\
\hline & GFAP+/MGMT- & 34 & 30.2 & 35.7 & 29.5 & 37.5 \\
\hline & GFAP-/MGMT+ & 10 & 3.8 & 16.7 & 4.5 & 12.5 \\
\hline & GFAP-/MGMT- & 13 & 0 & 19.0 & 0 & 25.0 \\
\hline
\end{tabular}

*Results refer to patients in whom tissue was available

\footnotetext{
(See figure on next page.)
}

Fig. 1 a Overall survival function comparing MGMT promoter methylated tumors with unmethylated tumors. Hypermethylation of the MGMT promoter region was associated with an increase in OS $(p=0.0012)$. Survival in both groups is longer compared to an unselected group of $G B$ patients due to the artificially high number of long-term survivors (55 patients; $37.4 \%$ ). All patients with available MGMT data are Included in this graph $(n=147)$. $\mathbf{b}$ Overall survival function comparing tumors which were at least partially negative for GFAP with tumors in which samples stained positive for GFAP. The difference between the groups was significant $(p=0.0022)$. As in $\mathbf{a}$, survival in both groups is longer compared to an unselected group of GB patients due to the artificially high number of long-term survivors (72 patients; $34.3 \%$ ). All patients with available GFAP data are included in this graph $(n=210)$

factors have been reported to be associated with OS in patients with GB. Specifically, resection compared to biopsy or subtotal resection, female sex, higher performance status, application of chemoradiation, and MGMT status among others have been suggested as prognostic for OS in multiple studies [23-25]. To control for these factors, we chose a matched-pair design with one LTS group matched to two STS groups; unfortunately, we could only identify 80 matches for the 2nd (control) STS group which was therefore matched with an 80-patient fraction of the LTS group.

Using this approach, we observed an increased frequency of IDH1 R132H mutations in the LTS group compared to STS-1. The difference was not significant in the second comparison with STS-2; therefore, we could not explicitly confirm the previously described prognostic significance of IDH1 mutational status [26] in our dataset. The literature is inconsistent on the relevance of the tumor growth fraction in GB [12-15]; samples of patients in the LTS group had lower growth fraction indices compared to STS-1; however, despite a consistent numerical trend, the difference was not significant in the control analysis between LTS and STS-2.

In contrast, we corroborated the association of MGMT promoter hypermethylation [23-25] in our dataset as the LTS group contained a significantly increased frequency of methylated tumors compared to both STS-1, and STS-2. The frequency of GFAP-positive tumors was also significantly increased in the LTS group compared to both STS groups. Interestingly, both factors were not associated with each other and positivity for both was associated with the best, while negativity for both with the worst OS outcomes in our cohort, indicating an association of GFAP with OS which occurs independently of $M G M T$ promoter hypermethylation.

The association of GFAP with OS is consistent with the loss of GFAP in high-grade tumors $[18,19]$ and increased tumor growth [20]; however, more recently, the relevance of different isoforms of GFAP [27] and an upregulation of GFAP in non-neoplastic astrocytes as a reaction to tumor growth have also been described by different groups [28, 29]. 
a)

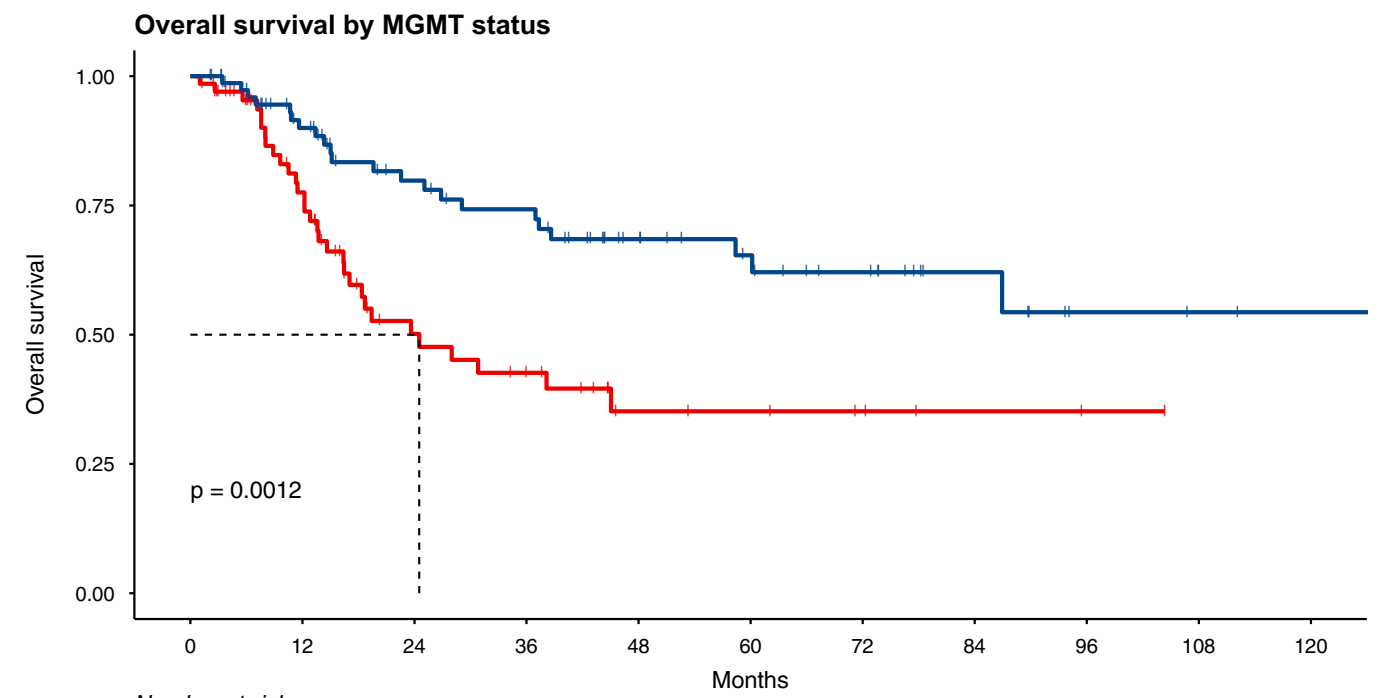

Number at risk

$\begin{array}{rrrrrrrrrrrr}\text { MGMT unmeth } & 68 & 42 & 20 & 15 & 7 & 6 & 4 & 2 & 1 & 0 \\ \text { MGMT meth } & 79 & 59 & 44 & 39 & 26 & 20 & 15 & 8 & 3 & 2 \\ & 0 & 12 & 24 & 36 & 48 & 60 & 72 & 84 & 96 & 1\end{array}$

Strata + MGMT unmeth - MGMT meth

b)

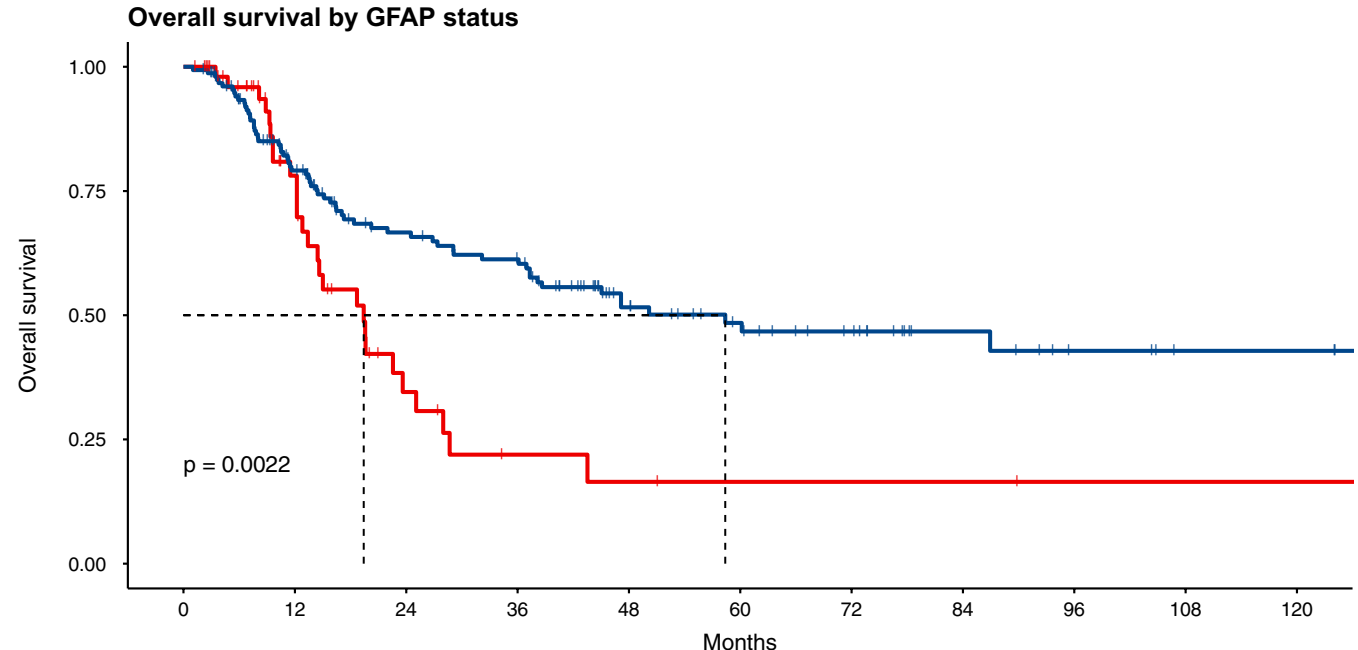

Number at risk

$\begin{array}{rccccccccccc}\text { GFAP neg } & 55 & 28 & 9 & 4 & 3 & 2 & 2 & 2 & 1 & 1 & 1 \\ \text { GFAP pos } & 155 & 105 & 75 & 67 & 37 & 28 & 21 & 12 & 7 & 4 & 4 \\ & 0 & 12 & 24 & 36 & 48 & 60 & 72 & 84 & 96 & 108 & 120\end{array}$

Strata + GFAP neg + GFAP pos

Fig. 1 (See legend on previous page.) 


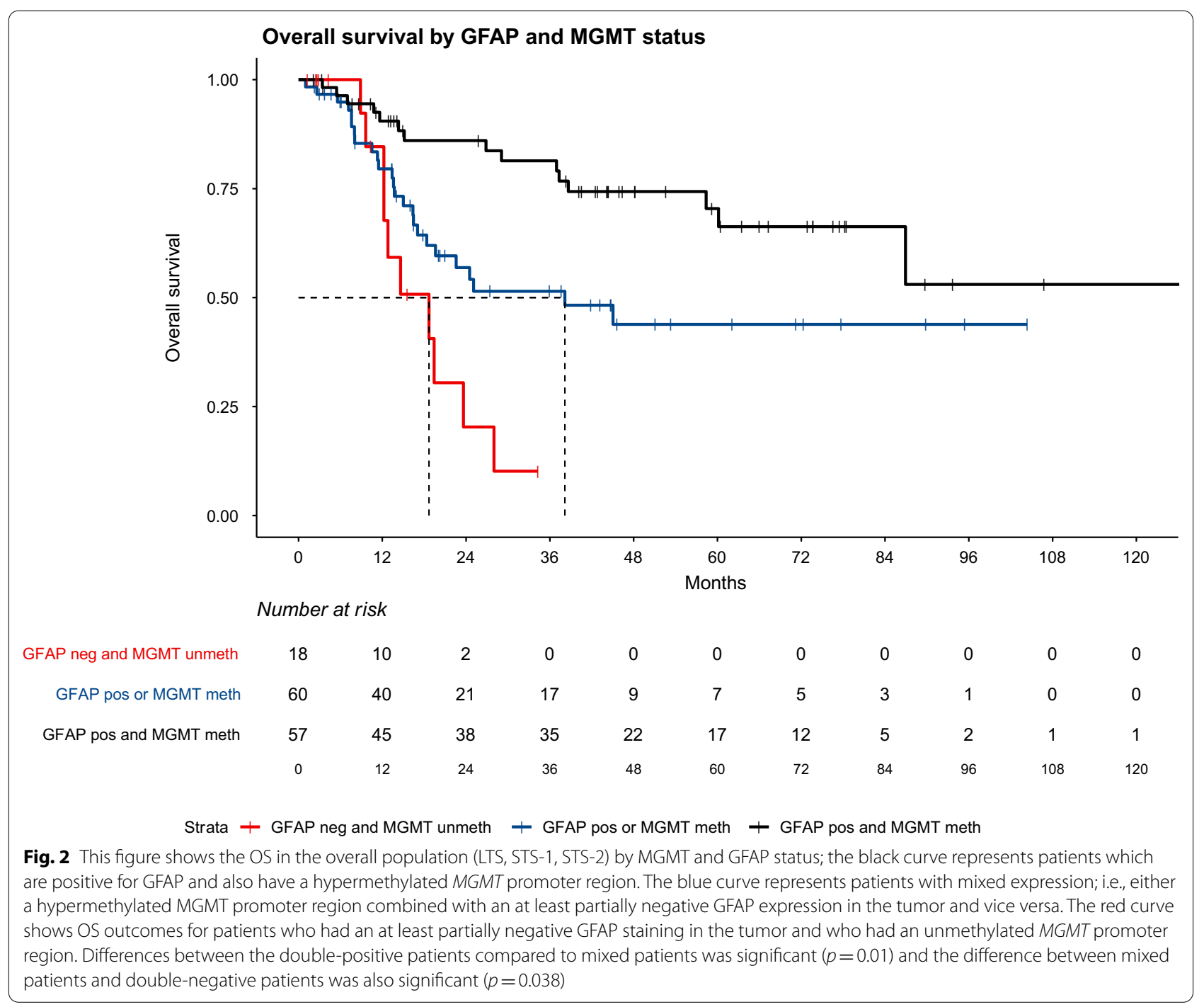

Our study has several limitations such as its retrospective nature which should be replicated in a prospective design; furthermore, a small proportion of LTS patients remained without a 2 nd match, possibly impairing statistical power of the analysis. A preferrable approach would have included using a control dataset for both LTS and STS; however, we could not identify a sufficient number of patients for this end. Furthermore, the 2021 WHO classification of brain tumors updated the classification of glioblastoma to exclude IDH-mutant tumors [30]. Our study was conducted before this classification was implemented and all groups include patients with tumors classified as IDH-mutant glioblastoma which would now be classified as IDH-mutant astrocytoma (grade 4). For our study, we used histopathological data from routine clinical analysis; therefore, some panels or molecular data were missing. Finally, there was no central image review and no central histopathology review for the study; however, all patients were treated within the framework of an interdisciplinary tumor board setting which included imaging and histopathology reviews.

Despite these shortcomings, our study provides evidence for a prognostic role of GFAP positivity in GB tissue and further corroborates MGMT methylation as a prognostic marker for OS.

\section{Conclusion}

We observed a significant association of MGMT promoter hypermethylation and GFAP expression with LTS in this cohort of GB patients. Given the hypothesis-generating nature of our study, these observations should be confirmed in prospective clinical trials.

\section{Abbreviations}

GB: Glioblastoma; GFAP: Glial fibrillary acidic protein; IDH-1: Isocitrate dehydrogenase 1; KPS: Karnofsky-performance-status; LTS: Long-term survivor; MGMT: 
O6-methylguanine-DNA methyltransferase; MIB-1: Molecular immunology Borstel-1; OS: Overall survival; PFS: Progression-free survival; STS: Short-term survivor; WHO: World Health Organization.

\section{Supplementary Information}

The online version contains supplementary material available at https://doi. org/10.1186/s13014-022-01984-w.

Additional file 1: figure S1. a) Overall survival in long-term survivors compared to short-term survivors-1. b) Overall survival in long-term survivors compared to short-term survivors-2.

\section{Acknowledgements}

We thank Svetlana Hetjens for statistical advice.

\section{Authors' contributions}

FG designed and directed the project. NM, SB, DH, FW and KP supplied the patient's information and helped collect all relevant data. M-CG an DR provided histopathological details. VNS acquired the dataset and worked with DB on the analysis and interpretation of results. DB was a major contributor in drafting the manuscript and all authors read and approved the final manuscript. GRS provided medical advice for the medical interpretation of data and helped to analyze the dataset for an interim analysis.

\section{Funding}

Open Access funding enabled and organized by Projekt DEAL. This work was funded in part by the Deutsche Forschungsgemeinschaft (DFG) within the SFB1389 ("Understanding and Targeting Resistance in Glioblastoma").

\section{Availability of data and materials}

The dataset generated and analyzed in the current study are available from the corresponding author on reasonable request.

\section{Declarations}

\section{Ethics approval and consent to participate}

The study was approved by the ethics committee of Heidelberg University, Medical Faculty Mannheim (2013-832R-MA). Written informed consent for scientific usage of clinical data was obtained from all patients.

\section{Consent for publication}

Not applicable.

\section{Competing interests}

DB reports personal fees from NB Capital ApS, personal fees from Nordic Biotech, personal fees from Siemens AG, personal fees from b.e. Imaging $\mathrm{GmbH}$, outside the submitted work; FG reports research grants and travel expenses from ELEKTA AB; grants, stocks, travel expenses and honoraria from NOXXON Pharma AG; research grants, travel expenses and honoraria from Carl Zeiss Meditec AG; travel expenses and honoraria from Bristol-Myers Squibb, Roche Pharma AG, MSD Sharp and Dohme GmbH and AstraZeneca GmbH; non-financial support from Oncare GmbH and Opasca GmbH. GRS: Grants and personal fees from Carl Zeiss Meditec AG; personal fees from Roche Pharma AG. All other authors report no conflicts of interest.

\section{Author details}

${ }^{1}$ Department of Radiation Oncology, University Medical Center Mannheim, University of Heidelberg, Heidelberg, Germany. ${ }^{2}$ Department of Neurosurgery, University Medical Center Mannheim, University of Heidelberg, Heidelberg, Germany. ${ }^{3}$ Department of Neuropathology, Institute of Pathology, University of Heidelberg, Heidelberg, Germany. ${ }^{4}$ Department of Radiation Oncology, University Hospital Bonn, University of Bonn, Venusberg-Campus 1, 53127 Bonn, Germany. ${ }^{5}$ Department of Pathology, Montreal Neurological Institute, Montreal, Canada. ${ }^{6}$ Department of Neurosurgery, Heinrich-Heine-Universität, Düsseldorf, Germany. ${ }^{7}$ Freiburg Medical Center, Freiburg, Germany. ${ }^{8}$ Department of Neurosurgery, Montreal Neurological Institute, Montreal, Canada.
Received: 28 June 2021 Accepted: 9 January 2022

Published online: 24 January 2022

\section{References}

1. Ostrom QT, Gittleman H, Farah P, Ondracek A, Chen Y, Wolinsky Y, et al. CBTRUS statistical report: primary brain and central nervous system tumors diagnosed in the United States in 2006-2010. Neuro Oncol. 2013;15 Suppl 2:ii1-56.

2. Stupp R, Hegi ME, Mason WP, van den Bent MJ, Taphoorn MJB, Janzer RC, et al. Effects of radiotherapy with concomitant and adjuvant temozolomide versus radiotherapy alone on survival in glioblastoma in a randomised phase III study: 5-year analysis of the EORTC-NCIC trial. Lancet Oncol. 2009;10(5):459-66.

3. Stupp R, Mason WP, van den Bent MJ, Weller M, Fisher B, Taphoorn MJ, et al. Radiotherapy plus concomitant and adjuvant temozolomide for glioblastoma. N Engl J Med. 2005;352(10):987-96.

4. Koshy M, Villano JL, Dolecek TA, Howard A, Mahmood U, Chmura SJ, et al. Improved survival time trends for glioblastoma using the SEER 17 population-based registries. J Neurooncol. 2012;107(1):207-12.

5. Krex D, Klink B, Hartmann C, von Deimling A, Pietsch T, Simon M, et al. Long-term survival with glioblastoma multiforme. Brain. 2007;130(Pt 10):2596-606.

6. Sonoda Y, Kumabe T, Watanabe M, Nakazato Y, Inoue T, Kanamori M, et al. Long-term survivors of glioblastoma: clinical features and molecular analysis. Acta Neurochir (Wien). 2009;151(11):1349-58.

7. Louis DN, Perry A, Reifenberger G, von Deimling A, Figarella-Branger D, Cavenee WK, et al. The 2016 World Health Organization classification of tumors of the central nervous system: a summary. Acta Neuropathol. 2016;131(6):803-20.

8. Hartmann C, Meyer J, Balss J, Capper D, Mueller W, Christians A, et al. Type and frequency of IDH1 and IDH2 mutations are related to astrocytic and oligodendroglial differentiation and age: a study of 1,010 diffuse gliomas. Acta Neuropathol. 2009;118(4):469-74.

9. Hegi ME, Diserens AC, Gorlia T, Hamou MF, de Tribolet N, Weller M, et al. MGMT gene silencing and benefit from temozolomide in glioblastoma. N Engl J Med. 2005;352(10):997-1003.

10. Hegi ME, Liu L, Herman JG, Stupp R, Wick W, Weller M, et al. Correlation of O6-methylguanine methyltransferase (MGMT) promoter methylation with clinical outcomes in glioblastoma and clinical strategies to modulate MGMT activity. J Clin Oncol. 2008;26(25):4189-99.

11. Zhao H, Wang S, Song C, Zha Y, Li L. The prognostic value of MGMT promoter status by pyrosequencing assay for glioblastoma patients' survival: a meta-analysis. World J Surg Oncol. 2016;14(1):261.

12. Hsu DW, Louis DN, Efird JT, Hedley-Whyte ET. Use of MIB-1 (Ki-67) immunoreactivity in differentiating grade II and grade III gliomas. J Neuropathol Exp Neurol. 1997;56(8):857-65.

13. Bredel M, Piribauer M, Marosi C, Birner P, Gatterbauer B, Fischer I, et al. High expression of DNA topoisomerase Ilalpha and Ki-67 antigen is associated with prolonged survival in glioblastoma patients. Eur J Cancer. 2002;38(10):1343-7.

14. Wong E, Nahar N, Hau E, Varikatt W, Gebski V, Ng T, et al. Cut-point for Ki-67 proliferation index as a prognostic marker for glioblastoma. Asia Pac J Clin Oncol. 2019;15(1):5-9.

15. Ho DM, Hsu CY, Ting LT, Chiang H. MIB-1 and DNA topoisomerase II alpha could be helpful for predicting long-term survival of patients with glioblastoma. Am J Clin Pathol. 2003;1 19(5):715-22.

16. Jung CS, Foerch C, Schanzer A, Heck A, Plate KH, Seifert V, et al. Serum GFAP is a diagnostic marker for glioblastoma multiforme. Brain. 2007;130(Pt 12):3336-41.

17. Tichy J, Spechtmeyer S, Mittelbronn M, Hattingen E, Rieger J, Senft C, et al. Prospective evaluation of serum glial fibrillary acidic protein (GFAP) as a diagnostic marker for glioblastoma. J Neurooncol. 2016;126(2):361-9.

18. Jacque CM, Vinner C, Kujas M, Raoul M, Racadot J, Baumann NA. Determination of glial fibrillary acidic protein (GFAP) in human brain tumors. J Neurol Sci. 1978;35(1):147-55.

19. Jacque CM, Kujas M, Poreau A, Raoul M, Collier P, Racadot J, et al. GFA and $\mathrm{S} 100$ protein levels as an index for malignancy in human gliomas and neurinomas. J Natl Cancer Inst. 1979;62(3):479-83. 
20. Hara A, Sakai N, Yamada H, Niikawa S, Ohno T, Tanaka T, et al. Proliferative assessment of GFAP-positive and GFAP-negative glioma cells by nucleolar organizer region staining. Surg Neurol. 1991;36(3):190-4.

21. Wilhelmsson U, Eliasson C, Bjerkvig R, Pekny M. Loss of GFAP expression in high-grade astrocytomas does not contribute to tumor development or progression. Oncogene. 2003;22(22):3407-11.

22. R Core Team. R: a language and environment for statistical computing. Vienna, Austria: R Foundation for Statistical Computing; 2020.

23. Trifiletti DM, Alonso C, Grover S, Fadul CE, Sheehan JP, Showalter TN. Prognostic implications of extent of resection in glioblastoma: analysis from a large database. World Neurosurg. 2017;103:330-40

24. Filippini G, Falcone C, Boiardi A, Broggi G, Bruzzone MG, Caldiroli D, et al. Prognostic factors for survival in 676 consecutive patients with newly diagnosed primary glioblastoma. Neuro Oncol. 2008;10(1):79-87.

25. Stark AM, van de Bergh J, Hedderich J, Mehdorn HM, Nabavi A. Glioblastoma: clinical characteristics, prognostic factors and survival in 492 patients. Clin Neurol Neurosurg. 2012;114(7):840-5.

26. Hartmann C, Hentschel B, Wick W, Capper D, Felsberg J, Simon M, et al. Patients with IDH1 wild type anaplastic astrocytomas exhibit worse prognosis than IDH1-mutated glioblastomas, and IDH1 mutation status accounts for the unfavorable prognostic effect of higher age: implications for classification of gliomas. Acta Neuropathol. 2010;120(6):707-18

27. van Bodegraven EJ, van Asperen JV, Robe PAJ, Hol EM. Importance of GFAP isoform-specific analyses in astrocytoma. Glia. 2019;67(8):1417-33.

28. Gullotta F, Schindler F, Schmutzler R, Weeks-Seifert A. GFAP in brain tumor diagnosis: possibilities and limitations. Pathol Res Pract. 1985;180(1):54-60.

29. Yoshii Y, Narushima K, Tsurushima H, Yanaka K, Hyodo A, Nose T, et al. Morphometrical analysis of GFAP-positive cells in human astrocytomas. Neurol Med Chir (Tokyo). 1992;32(8):554-8.

30. Louis DN, Perry A, Wesseling P, Brat DJ, Cree IA, Figarella-Branger D, et al. The 2021 WHO classification of tumors of the central nervous system: a summary. Neuro Oncol. 2021;23(8):1231-51.

\section{Publisher's Note}

Springer Nature remains neutral with regard to jurisdictional claims in published maps and institutional affiliations.

Ready to submit your research? Choose BMC and benefit from:

- fast, convenient online submission

- thorough peer review by experienced researchers in your field

- rapid publication on acceptance

- support for research data, including large and complex data types

- gold Open Access which fosters wider collaboration and increased citations

- maximum visibility for your research: over $100 \mathrm{M}$ website views per year

At BMC, research is always in progress.

Learn more biomedcentral.com/submissions 